\title{
The Antisense Oligonucleotide Nusinersen for Treatment of Spinal Muscular Atrophy
}

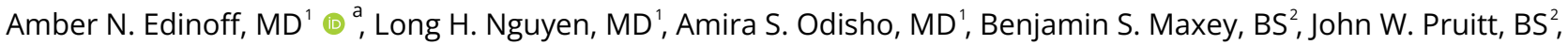
Brook Girma, MD³, Elyse M. Cornett, PhD ${ }^{3}$, Adam M. Kaye, PharmD ${ }^{4}$, Alan D. Kaye, MD, PhD ${ }^{3}$

1 Department of Psychiatry and Behavioral Medicine, Louisiana State University Health Science Center Shreveport, 2 School of Medicine, Louisiana State University Health Science Center Shreveport, ${ }^{3}$ Department of Anesthesiology, Louisiana State University Health Science Center Shreveport, 4 Department of Pharmacy Practice, Thomas J. Long School of Pharmacy and Health Sciences, University of the Pacific

Keywords: nusinersen, antisense oligonucleotide, smn1, spinal muscular atrophy

https://doi.org/10.52965/001c.24934

\section{Orthopedic Reviews}

Vol. 13, Issue 1, 2021

Spinal muscular atrophy (SMA) is a rare, autosomal recessive neuromuscular degenerative disease characterized by loss of spinal cord motor neurons leading to progressive muscle wasting. The most common pathology results from a homozygous disruption in the survival motor neuron 1 (SMN1) gene on chromosome 5 q13 via deletion, conversion, or mutation. SMN2 is a near duplicate of SMN1 that can produce full-length SMN mRNA transcripts, but its overall production capability of these mRNA transcripts is lower than that seen in SMN1. This leads to lower levels of functional SMN protein within motor neurons. The FDA approved nusinersen in December 2016 to treat SMA associated with SMN1 gene mutation. It is administered directly to the central nervous system by intrathecal injection. An antisense oligonucleotide (ASO) drug, nusinersen, provides an upcoming and promising treatment option for SMA and represents a novel pharmacological approach with a mechanism of action relevant for other neurodegenerative disorders. Nusinersen begins with four initial loading doses that are followed by three maintenance doses per year. Three major studies (CHERISH, ENDEAR, and NURTURE) have shown to improve motor function in early and late-onset individuals and reduce the chances of ventilator requirements in pre-symptomatic infants. Studies investigating the timing of drug delivery in mouse models of SMA report the best outcomes when drugs are delivered early before any significant motor function is lost. Nusinersen is a novel therapeutic approach with consistent results in all three studies and is proof of the novel concept for treating SMA and other neurodegenerative disorders in the future.

\section{INTRODUCTION}

Spinal muscular atrophy (SMA) is a rare, autosomal recessive neuromuscular degenerative disease characterized by loss of spinal cord motor neurons leading to progressive muscle wasting. The most common pathology results from a homozygous disruption in the survival motor neuron 1 (SMN1) gene on chromosome $5 \mathrm{q} 13$ via deletion, conversion, or mutation. ${ }^{1}$ In a large multi-ethnic study to test the feasibility of high-throughput genetic testing for SMA carriers, the overall carrier frequency was established as 1 in 54 with an incidence of 1 in $11,000 .^{2}$ SMA is broken down into various levels of severity with classification into four main phenotypes based on age and level of motor function. Type 1 is considered the most severe and seen within six months of life. It presents with hypotonia, areflexia, and significant muscle weakness. The FDA approved nusinersen in December 2016 to treat SMA associated with SMN1 gene mutation. It is administered directly to the central nervous system by intrathecal injection. Nusinersen became the first approved treatment for SMA with an orphan drug designation in the United States and Europe. An antisense oligonucleotide (ASO) drug, nusinersen, provides an upcoming and promis-

\footnotetext{
Corresponding Author:

Dr. Amber Edinoff, MD

Louisiana State University Health Science Center Shreveport

Department of Psychiatry and Behavioral medicine

1501 Kings Hwy

Shreveport, LA 71103

Phone: (318) 675-8969

aedino@lsuhsc.edu
} 
ing treatment option for SMA and represents a novel pharmacological approach with a mechanism of action relevant for other neurodegenerative disorders. ${ }^{3}$ ASO therapies inhibit gene expression by binding to messenger RNA (mRNA), causing them to be cut into pieces that intervene with the creation of coded proteins. The principal pharmacological action mechanism of the 2'-O-methoxyethyl phosphorothioate modified drug nusinersen alters the SMN2 pre-mRNA splicing process by inhibiting splicing factors. ${ }^{3}$ Nusinersen increases exon 7 inclusions in survival motor neuron 2 (SMN2) mRNA transcripts, which increases the production of full-length SMN proteins. Three major studies (CHERISH, ENDEAR, and NURTURE) have shown to improve motor function in early and late-onset individuals and reduce the chances of ventilator requirements in pre-symptomatic infants. Nusinersen begins with four initial loading doses that are followed by three maintenance doses per year. The more common side effects of nusinersen include lower respiratory infection, fever, constipation, headache, vomiting, back pain, post-lumbar puncture syndrome, increase risk of kidney damage, and bleeding complications. If indicated, Nusinersen is a viable option to treat SMA as it is one of the few SMN enhancing medications available today.

\section{SPINAL MUSCULAR ATROPHY}

\section{EPIDEMIOLOGY}

Estimating the prevalence and incidence of SMA has a unique set of challenges to consider. Many studies that attempted to quantify SMA epidemiology were performed before discovering the genetic cause behind SMA, forcing older studies to rely on clinical features alone. ${ }^{4}$ Additionally, many studies were conducted in small geographic locations where a mildly elevated population with SMA can drastically affect the final calculations of incidence and prevalence. ${ }^{4-6}$ Nonetheless, SMA of any type is a rare disease with an estimated incidence of roughly 10 in 100,000 live births. ${ }^{4}$ When all types of SMA are considered together, the prevalence is estimated to be approximately 1-2 per 100,000 persons. ${ }^{4}$ Type 1 SMA is the deadliest form of the disease and presents an inherent challenge in assessing its prevalence as patients often die as early as one year of age. ${ }^{4}$ The prevalence of SMA type 1 is estimated to be between 0.04 and 0.28 per 100,000 , but the accuracy of these figures is limited by the short life span in these patients. ${ }^{4,7,8}$ This contrasts with the milder forms of SMA, types 2 and 3 , where patients often survive into early adulthood and beyond, allowing better prevalence estimates. Taking SMA type 2 and 3 together, prevalence is nearly 1.5 per $100,000.4,9$

\section{PATHOPHYSIOLOGY}

The pathophysiology of all types of SMA originates from a homozygous deletion of the SMN1 gene present on chromosome $5 \mathrm{q} 13$ that functions to produce survival motor neuron (SMN) proteins. ${ }^{10}$ Humans have two forms of this gene: the telomeric (SMN1) and the centromeric (SMN2). ${ }^{10}$ SMN2 is nearly identical to SMN1 but is a poor replacement in SMA patients as a single substitution at position 840 leads to the exclusion of exon 7 when transcribed. ${ }^{10}$ As a result, this mRNA missing exon 7 produces a shortened, nonfunctional protein quickly degraded. ${ }^{10}$ However, the exclusion of exon 7 is incomplete as $10-15 \%$ of the mRNA transcripts from SMN2 retain exon 7; these mRNA transcripts encode the normal functional SMN protein and provide some but reduced functionality. ${ }^{10}$

SMN protein is a ubiquitous protein present in the cytoplasm and nucleus as a part of a complex vital to small nuclear ribonuclear protein (snRNPs) production. ${ }^{10}$ The snRNPs are involved in the splicing of pre-mRNA into mRNA and are essential in various cellular housekeeping functions. ${ }^{11}$ Due to this functional importance, the therapeutic focus is shifted to the function of SMN proteins and how they make lower motor neurons susceptible to degeneration. One study suggests that low levels of SMN protein create a negative feedback loop specific to lower motor neurons where decreases in exon 7 inclusion further decrease the splicing of its mRNA. ${ }^{11,12}$ Other studies suggest that SMN's role in axonal transport and actin dynamics may contribute to the motor neuron-specific pathology. ${ }^{11,13,14}$ Nonetheless, SMN's involvement in multiple pathways and cellular functions points to motor neuron degeneration as the final common outcome from multiple upstream causes. ${ }^{11}$

\section{RISK FACTORS}

An autosomal recessive disease, the risk of developing SMA is associated with a carrier frequency in the population. An analysis looking at different ethnicities over multiple geographic locations discovered Caucasians and Asians generally possess higher carrier frequencies for SMN1 mutations but were not significantly higher than those of other ethnic groups. ${ }^{4}$ Notable risk factors for developing SMA were identified, including consanguinity. One study of an Egyptian community where over half of the affected families displayed some degree of consanguinity identified an incidence of 250 in 100,000 live births. ${ }^{4}$

Risk factors for the progression of SMA to its most severe life-threatening complications were later analyzed. The most life-threatening point of progression was feeding problems. ${ }^{15}$ These include behaviors such as difficulties with chewing, choking while eating, and dysphagia. ${ }^{15}$ While some of these difficulties may not develop in the milder forms of SMA (types 2 and 3), they almost always are seen in those with type $1 .{ }^{15}$ One study illustrated that as high as $44 \%$ of patients with SMA type 2 and 3 develop some sort of feeding difficulty, and 10\% will develop aspiration leading to hospitalization. 15

\section{CLINICAL PRESENTATION}

Although the lack of SMN1 genotypically defines SMA, the clinical presentation and the overall severity of the disease state are determined mainly by the copy number of the SMN2 gene in the patient's genome. ${ }^{16}$ Patients will possess variable copy numbers between 0 and 8 of the SMN2 gene, 
where more significant numbers of SMN2 correlate with more severity. ${ }^{11}$ SMN2 is a near duplicate of SMN1 that can produce full-length SMN mRNA transcripts, but its overall production capability of these mRNA transcripts is lower than that seen in SMN1. This leads to lower levels of functional SMN protein within motor neurons. ${ }^{16}$ Patients with SMA type 1, the most severe form of the disease, will present in the first few months of life with lower motor neuron signs such as extremity weakness, absent deep tendon reflexes, and intercostal muscle weakness with intact sensations. ${ }^{16}$ Historically, those with type 1 have died within the first few years of life as muscle weakness eventually led to feeding difficulties, consequential failure to thrive, and swallowing dysfunction with an ensuing risk of aspiration. ${ }^{16}$ Patients with SMA type 2 have a less severe but still debilitating presentation that usually starts between 6 and 18 months old. ${ }^{16}$ Patients with type 2 SMA left untreated will lose the ability to stand and walk independently and possess the same risk for respiratory and feeding difficulties as type 1 but at a slower onset and have a more mild muscle weakness. ${ }^{1,16}$ Type 3 and 4 are considered the mildest forms of SMA. Patients with type 3 have sufficient copies of SMN2, allowing adequate production of functional SMN protein, and often can avoid the severe life-threatening complications seen in those with type $1 .{ }^{16}$ Patients may develop gross motor skills normally initially. Still, after 18 months of age, they present with falls and regression that may worsen over time. ${ }^{16}$ SMA type 4 , the least debilitating of the four, often presents in adulthood with highly variable motor symptomology, making it a difficult diagnostic case as other neurologic diseases must first be ruled out. ${ }^{1}$ Although the copy number of SMN2 is the primary factor in determining the severity of the illness. Phenotypic variations can occur from certain exon 7 mutations, creating splice-enhancing elements and more functional SMN protein production..$^{10}$ This pathology is less common but shows how various changes in SMA genotypes can clinically present.

\section{CURRENT TREATMENT OF SPINAL MUSCULAR ATROPHY}

\section{MANAGEMENT OF COMPLICATIONS}

The leading cause of morbidity and mortality among patients with SMA is respiratory complications such as impaired coughing ability, hypoventilation (especially during sleep), recurrent infections, and hypoplasia of the lungs and chest wall. ${ }^{17,18}$ These symptoms are caused mainly by progressive weakening of expiratory and intercostal muscles with mostly preserved diaphragm innervation. ${ }^{17}$ Monitoring respiratory muscle functions quantitatively with peak cough flow, maximal inspiratory pressures, and maximal expiratory pressures is often difficult as many patients are too young or too weak to undergo testing. Respiratory functions can be gauged more practically through a targeted physical exam that assesses respiratory rate, work of breathing, presence of paradoxical breathing, and presence of cyanosis or pallor. ${ }^{17,18}$ Respiratory support include assistance in airway clearance (e.g., manual cough assist, mechanical insufflation-exsufflation, postural drainage), noninvasive ventilation, and, in severe cases, tracheostomy. ${ }^{17}$

Nutritional deficits associated with SMA stem from bulbar dysfunction, which impairs swallowing capability. Those with SMA types 1 or 2 are at increased risk of malnutrition, and those with less severe symptoms are at higher risk of obesity. ${ }^{17}$ Swallowing difficulties may be managed with semisolid diets or feeding through nasogastric or gastrostomy tubes, either as a supplement or replacement for oral feeding. ${ }^{17}$ Another major cause of morbidity and mortality for SMA patients is the increased risk for gastroesophageal reflux, putting patients at a higher risk for silent aspiration, consequent pneumonia, and other respiratory complications. ${ }^{18-20}$ Reflux can be managed with antacids and agents that block acid secretion, such as proton pump inhibitors or histamine blockers. ${ }^{17,20}$

A large portion of SMA patients will develop orthopedic disorders, including joint contractures, hip subluxation or dislocation, scoliosis, and mobility difficulties. Physical therapy, mobility equipment, orthoses, and braces can alleviate most of these disorders, whereas more severe instances of scoliosis and hip subluxation/dislocation warrant surgery. ${ }^{18}$ Scoliosis is particularly concerning as it is present in roughly $60-95 \%$ of SMA patients, and the progression of scoliosis can exacerbate respiratory dysfunction and gastroesophageal reflux. ${ }^{18,21}$ Surgical intervention is most often indicated for progressive scoliosis in patients with SMA types 2 or 3 . While surgical correction cannot reverse losses in lung capacity resulting from scoliosis, the correction significantly improves the quality of life and slows further deterioration of respiratory function. ${ }^{22,23}$ After skeletal maturity in adolescence, patients often undergo posterior spinal fusion with iliac fixation to assist correction of pelvic obliquity. ${ }^{18}$

\section{PHARMACOLOGIC TREATMENTS}

Over the past two decades, several pharmacologic agents have been investigated as potential treatments for SMA. The main treatment strategies can be categorized into four groups: promoting the survival of motor neurons, enhancing muscular function, introducing exogenous copies of the $S M N 1$ gene, and modulating transcription of the SMN2 gene to produce full-length gene products.

One neuroprotective agent, olesoxime, acts by decreasing the permeability of mitochondrial membranes during stress, inhibiting the release of pro-apoptotic factors and promoting the survival of motor neurons. ${ }^{24,25}$ Olesoxime showed early promise in cell cultures and mouse models, but a phase II clinical trial failed to meet its primary endpoint, causing an abrupt stop in the development of the drug in 2018.18,24,26 Other neuroprotective agents like gabapentin and riluzole were briefly investigated as treatments for SMA in the early 2000s, but data from early clinical trials did not support the drug's efficacy in treating SMA. ${ }^{27-29}$

The fast skeletal muscle troponin activator, reldesemtiv, increases contractility and limits fatigue by slowing calcium release from troponin in fast skeletal muscle fibers. ${ }^{24,25,30}$ 
Phase II clinical trials showed significant increases from baseline on 6-minute walk distances and maximal expiratory pressure for patients with SMA types 2, 3, and 4. Still, several other measures of neuromuscular function illustrated no significant change. ${ }^{25,30-32}$ Further studies are in the planning stages and may involve a combination of reldesemtiv with other therapies. ${ }^{30}$ Pyridostigmine (an acetylcholinesterase inhibitor) and SRK-015 (a myostatin inhibitor) are also currently under investigation for SMA treatment. Both are now in phase II clinical trials, with the final results pending. ${ }^{33,34}$

The next class of treatments aims to correct the underlying genetic defect in SMA rather than improving neuromuscular function. Two small molecule drugs, branaplam and risdiplam, act by promoting the inclusion of exon 7 of the SMN2 gene during transcription, increasing levels of fulllength SMN proteins. ${ }^{30}$ Branaplam showed early promise in its safety and efficacy, but development was halted briefly after preclinical toxicology studies showed nerve damage as a possible side effect. ${ }^{35,36}$ This issue has then been resolved, and phase I/II trials are currently developing the drug. ${ }^{35}$ Risdiplam, in contrast, has demonstrated clear safety and efficacy and is now in phase II/III clinical trials. ${ }^{30}$ Nusinersen acts through a similar mechanism to promote the inclusion of exon 7 in SMN2 gene products, but the form of the drug is an antisense oligonucleotide rather than a small molecule. ${ }^{30}$ The mechanism of action of nusinersen will be explored in greater detail later in this review.

A more direct approach to correcting the genetic defect underlying SMA, zolgensma (known as AVXS-101), delivers an intact copy of the wild-type SMN1 gene through an adeno-associated viral serotype 9 (AAV9) vector. ${ }^{24}$ In phase I trials, zolgensma showed significant results in improving survival, motor function, and milestones in infant patients with SMA type 1, with the only notable side effect being transaminitis. ${ }^{37}$ Phase II and III clinical trials yielded similar positive results, and zolgensma was approved by the FDA in May 2019 for intravenous administration in SMA patients under two years of age. Additional trials are underway for intrathecal administration and the use of zolgensma in pre-symptomatic patients. Currently, zolgensma and nusinersen are the only two FDA-approved direct treatments for SMA. ${ }^{24}$

Early detection and diagnosis of SMA are critical in preventing irreversible loss of motor function and muscular atrophy. For patients with the most severe form of SMA (type 1), irreversible loss of motor neurons begins perinatally with loss of more than $90 \%$ of motor units within the first six months of life. ${ }^{25,38,39}$ Studies investigating the timing of drug delivery in mouse models of SMA report the best outcomes when drugs are delivered early before any significant motor function is lost. ${ }^{18,40}$ Obtaining the maximum benefit from any SMA treatment hinges on thorough newborn screening and early intervention.

\section{NUSINERSEN PHARMACOLOGIC CONSIDERATIONS}

Nusinersen has been approved and designated as a treatment for spinal muscular atrophy in all stages of life. Nusin- ersen was approved for all 5q-associated SMA types by the FDA in December 2016 and the European Medicines Agency (EMA) in July 2017. ${ }^{3}$ It is available as an injection administered directly to the central nervous system intrathecally by a trained health care provider. The recommended dosage of nusinersen is $12 \mathrm{mg}(5 \mathrm{~mL})$ per administration. It is usually given as four initial doses, once every two weeks for the first three doses and 30 days after the third dose. After the loading dose is complete, it is then given once every four months. Common side effects include lower respiratory infection, fever, constipation, headache, vomiting, back pain, and post-lumbar puncture syndrome. Regular blood and urine testing are required due to the increased risk of kidney damage and bleeding complication. Risks associated with pregnancy are not clearly defined due to a lack of sufficient data. No adverse effects on embryo-fetal development were observed in animal studies in which nusinersen was administered by subcutaneous injection to mice and rabbits during pregnancy. ${ }^{41}$ Clinical trials have determined the safety and efficacy of nusinersen on the pediatric population and have shown no effect in juvenile monkeys with $0.3 \mathrm{mg}$ per dose. Nusinersen has orphan drug designation in the United States and Europe.

\section{MECHANISM OF ACTION}

Nusinersen is a survival motor neuron-2 (SMN2)-directed antisense oligonucleotide (ASO) designed to treat SMA caused by a deficiency in SMN proteins secondary from mutations in chromosome $5 \mathrm{q} .{ }^{42}$ ASO therapies inhibit gene expression by binding to messenger RNA (mRNA); this facilitates breakdown and interferes with protein production. In vitro studies have shown nusinersen to increase exon 7 inclusion into the SMN2 mRNA transcripts, which enhances SMN protein production and increases the amount of full-length SMN proteins. The 2'-O-methoxyethyl phosphorothioate ASO seen in nusinersen inhibits splice-altering oligonucleotides on SMN2, displacing the intronic splice silencing site 1 (ISS-1) between exons 7 and 8 and allowing a complete translation of SMN protein for the SMN2 gene.

\section{PHARMACOKINETICS}

Nusinersen's pharmacokinetics within the CSF and CNS are of great importance to understanding its usefulness in treating SMA as the CNS tissues are nusinersen's main site of action. ${ }^{43}$ The pharmacokinetics can be analyzed using a four-compartment model that considers the drug's diffusion into and out of the CSF and CNS tissues. ${ }^{44}$ An analysis with ELISA and electrochemiluminescence quantifying levels of nusinersen in the CSF and CNS tissues illustrated the drug was rapidly taken up by CNS tissues (the cervical, thoracic, and lumbar spinal cord with low levels) and then was found in the CSF shortly. ${ }^{45}$ Furthermore, uptake into the lumbar area tissues from the CSF is nearly twice as fast as uptake within the cervical and thoracic regions. However, this may be due to the relatively higher concentration gradient at the injection site during a lumbar puncture. ${ }^{45}$ After the drug enters the CNS tissues, it must first move back into the CSF before being cleared into systemic circu- 
lation where it is no longer active. ${ }^{46}$ Nusinersen distributes from the CSF into CNS tissues 4 to 20 fold faster than it diffuses back out of these tissues during its clearance phase. ${ }^{45}$ This may help explain nusinersen's long median half-life of 163 days in the CSF and support dosing at intervals of 4-6 months. ${ }^{44,45}$ The plasma serves as the main clearance site for nusinersen by the action of exonuclease hydrolysis and urinary excretion, and current studies have not found the support of degradation by cytochrome P450 enzymes. ${ }^{43,46}$

\section{CLINICAL TRIALS: SAFETY AND EFFICACY}

\section{PHASE I STUDY}

In an open-label phase I study (NCT01494701), nusinersen was administered by intrathecal injection to patients with type 2 and type 3 SMA, aged 2-14 years. This study aimed to evaluate the safety, tolerability, pharmacokinetics, and preliminary efficacy of nusinersen. Ascending doses of 1, 3, 6, and $9 \mathrm{mg}$ were administered to a total of 28 participants $(\mathrm{n}=$ 6 in the first 3 dose cohorts, and $n=10$ in the $9 \mathrm{mg}$ cohort). The study began with the $1 \mathrm{mg}$ dose cohort, and then each dose level was evaluated for safety before proceeding to the next level. Periodic follow-ups included safety assessments (collection of adverse events, physical/neurologic examinations, vital signs, clinical laboratory tests, and ECGs) and collecting CSF and plasma samples to analyze safety and pharmacokinetics. For preliminary clinical outcome measurements, the Hammersmith Functional Motor Scale Expanded (HFMSE) and Pediatric Quality of Life Inventory were used. The drug was well-tolerated, with no serious adverse events reported and no clinically significant changes in vital signs, neurologic or physical examinations, clinical laboratory tests, or ECGs. Plasma and CSF drug levels were dose-dependent, and nusinersen's half-life in CSF was found to be 4-6 months. A significant increase in HFMSE scores was observed at the $9 \mathrm{mg}$ dose at 3 months post-dose (3.1 points; $p=0.016$ ), which increased even further at 9-14 months post-dose (5.8 points; $p=0.008$ ) during an extension study (NCT01780246). This study provided clear support for the safety and tolerability of nusinersen, as well as promising preliminary data on its efficacy. 47,48

\section{PHASE I/II STUDY}

In a 253-day open-label, multiple-dose, multicenter phase Ib/IIa study (NCT01703988) with a 715-day extension study (NCT02052791), the long-term efficacy and safety of nusinersen were investigated. Similar to the previous study, this clinical trial enrolled children between the ages of 2 and 15 years with type $2(n=11)$ and type $3(n=17)$ SMA and used an escalating dose (3, 6, 9, and $12 \mathrm{mg} ; \mathrm{n}=8, \mathrm{n}=8, \mathrm{n}$ $=9, \mathrm{n}=9$, respectively) format. Participants were administered 3 doses of intrathecal nusinersen on days 1, 29, and 85 of the study, and safety monitoring follow-ups were conducted on days 8, 36, 92, 169, and 253. Efficacy was measured through HFMSE scores, as well as Upper Limb Module (ULM), 6 Minute Walk Test (6MWT), compound muscle action potential (CMAP), and quantitative multipoint incremental motor unit number estimation. In the 715-day extension study, the participants were administered 4 doses of $12 \mathrm{mg}$ nusinersen at 6-month intervals, with safety mon- itoring visits occurring on days 8, 85, 260, 442, 624, and 715. After the study, Mean HFMSE scores, ULM scores, and 6MWT distances had improved (HFMSE: SMA type $2,+10.8$ points; SMA type $3,+1.8$ points; ULM: SMA type $2,+4.0$ points; 6MWT: SMA type 3, +92.0 meters). Mean CMAP values remained relatively stable, and zero children discontinued treatment due to adverse events. Data from this trial gave evidence of clinically significant long-term improvements in motor function and stabilization of disease activity in patients with later-onset SMA, as well as an acceptable safety profile for the drug. ${ }^{49,50}$

\section{PHASE II STUDIES}

While phase I trials focused on patients with later-onset SMA, phase II trials primarily explored the safety and efficacy of nusinersen in the treatment of infantile-onset SMA. One open-label dose-escalation study enrolled 20 infants (3 weeks -7 months of age) with type 1 SMA. This clinical trial aimed to establish a safety profile, study pharmacokinetics, and demonstrate efficacy in improving motor function and extending patients' lifespans. One cohort $(\mathrm{n}=4)$ was administered 3 doses of $6 \mathrm{mg}$ intrathecal nusinersen on days 1,15 , and 85 . The second cohort $(n=16)$ was administered $12 \mathrm{mg}$ doses on the same dosing schedule; both had periodic follow-ups to assess safety. Clinical efficacy was measured through event-free survival (time to death, or time to permanent assisted ventilation), change from baseline of compound muscle action potentials, and two assessments of motor function: the motor milestones portion of the Hammersmith Infant Neurological Exam-Part 2 (HINE-2) and the Children's Hospital of Philadelphia Infant Test of Neuromuscular Disorders (CHOP-INTEND) motor function test. Autopsy tissue was also analyzed for pharmacologic activity.

In the $12 \mathrm{mg}$ dose group, incremental achievements of motor milestones ( $p<0.0001)$, improvements in CHOP-INTEND motor function scores $(\mathrm{p}=0.0013)$, and increased compound muscle action potential amplitude of the ulnar nerve $(\mathrm{p}=0.0103)$ and peroneal nerve $(\mathrm{p}<0.0001)$, compared with baseline, were observed. The cohort's KaplanMeier survival curve also diverged from a published national history case series $(p=0.0014)$. Analysis of autopsy tissue from patients exposed to nusinersen showed drug uptake into motor neurons throughout the spinal cord, exposure at therapeutic concentrations, and increased SMN2 mRNA exon 7 inclusion and SMN protein concentrations in the spinal cord. All participants reported severe adverse events, but the authors considered all events to be unrelated to nusinersen. In all, this study showed acceptable safety of multiple-dose intrathecal nusinersen in SMA type 1 patients, demonstrated pharmacokinetics consistent with the drug's mechanism of action, and supported nusinersen's clinical efficacy. ${ }^{51}$

Patients with homozygous deletions in the SMN1 gene are expected to develop symptoms of SMA, with varying degrees of severity based on the number of intact gene copies of SMN2 present. ${ }^{52}$ Aiming to quantify nusinersen's ability in the proactive treatment of SMA, the NURTURE study (NCT02386553) investigated the efficacy of nusinersen for pre-symptomatic patients. 25 infants with documented 
SMN1 deletions were enrolled in the study, with 15 having two copies of SMN2 and 10 having three copies. All participants had no clinical signs or symptoms of SMA at the beginning of the study, were younger than the expected age of onset for symptoms in SMA types 1 and 2, and had baseline CMAP amplitudes of $\geqslant 1 \mathrm{mV}$. Nusinersen was administered in 4 loading doses of $12 \mathrm{mg}$ each on days $1,15,29$, and 64 of the study followed by maintenance dosing every 119 days. At the time of analysis, the participants were a median 34.8 months of age, past the expected age of symptom onset for SMA types 1 and 2 . All subjects were living, and none required tracheostomy or permanent ventilation. Four participants with two SMN2 copies utilized respiratory support for $\geqslant 6$ hours per day for $\geqslant 7$ consecutive days that was initiated during acute, reversible illnesses. All 25 participants achieved the ability to sit without support, $23 / 25$ achieved walking with assistance, and 22/25 achieved walking independently. Eight infants had adverse events possibly related to nusinersen. Drug-related adverse events may be a reason for mild concern. Still, overall, the data collected from this study indicate that the pre-symptomatic treatment of SMA can improve patients' outcomes through genetic testing. They highlight the importance of thorough newborn screening. A placebo-controlled trial would be required to claim absolute significance in the efficacy of the drug, but the study's results are promising, nonetheless. ${ }^{53}$

\section{PHASE III STUDIES}

Phase III studies on nusinersen generally follow the same structure as earlier clinical trials with the addition of a placebo-controlled group. The double-blind, placebo-controlled ENDEAR trial (NCT02193074) was mainly designed after the NURTURE study. ${ }^{53} 121$ infants $(n=80$ for the nusinersen group, $\mathrm{n}=41$ for the control group) with documented homozygous deletions of SMN1 were enrolled in the trial. However, all the participants were symptomatic at the time of enrollment in contrast to the NURTURE study. In the nusinersen group, the drug was administered in four doses of $12 \mathrm{mg}$ each on days 1, 15, 29, and 64 of the study, while the placebo group had sham procedures on the same days. The primary endpoints for this study were motor milestone responses (quantified by HINE-2 scores) as well as event-free survival. Efficacy assessments were scheduled on days $64,183,302$, and 394, and safety assessments were scheduled on the same days with the addition of days 16 and 30. A prespecified interim analysis after 80 infants had been enrolled for at least 6 months yielded a benefit-cost analysis favoring nusinersen. This prompted the early termination of the trial with any remaining assessments carried out at the end-of-study visit. The final analysis showed that a significantly higher percentage of infants in the nusinersen group than that in the control group had a motor-milestone response (37 of 73 infants [51\%] vs. 0 of 37 [0\%]). The likelihood of event-free survival was higher in the nusinersen group than that in the control group (hazard ratio for death or the use of permanent assisted ventilation, $0.53 ; \mathrm{p}=0.005$ ). The incidence rate of adverse events was similar between the two groups. Participants with a shorter duration of illness at the time of screening were more likely to benefit from treatment with nusinersen over those with a longer duration of illness, highlighting the great need for effective newborn screening and early detection. ${ }^{54}$ An additional trial, the Expanded Access Program (NCT02865109), sought to reinforce the results of the ENDEAR trial and confirm its validity for SMA type 1 patients older than 7 months. The study followed a very similar structure, and its results were consistent with the ENDEAR study's data in terms of safety and efficacy. ${ }^{55}$

The double-blind, placebo-controlled CHERISH trial (NCT02292537) followed a similar format, but the participants were children who had symptom onset after 6 months of age. Participants $(n=126 ; n=84$ for nusinersen group, $\mathrm{n}=42$ for control group) underwent intrathecal administration of $12 \mathrm{mg}$ of nusinersen (nusinersen group) or a sham procedure (control group) on days 1, 29, 85, and 274 of the trial. The primary endpoint for this study was changed from the baseline of HFMSE scores. Secondary endpoints include the percentage of participants with a clinically significant increase in HFMSE score ( $\geqslant 3$ points). Similar to the ENDEAR trial, the CHERISH trial included a prespecified interim analysis at 15 months. The interim analysis reported significant results in favor of nusinersen, which again prompted the early termination of the trial. The leastsquares mean an increase in HFMSE score from baseline to month 15 was 4.0 in the nusinersen group and -1.9 in the control group. In the final analysis, $57 \%$ of the nusinersen group had an increase in HFMSE score of $\geqslant 3$ points, in contrast to only $26 \%$ of the control group ( $p<0.001$ ). The incidence of adverse effects was similar in both groups. This trial served to reinforce the growing body of evidence that nusinersen is safe and effective for use in the treatment of all forms of SMA. 56

\section{CONCLUSION}

SMA, a neurodegenerative disease affecting spinal anterior horn cells, is a rare disease with an estimated incidence of roughly 10 in 100,000 live births and a prevalence estimated to be approximately $1-2$ per 100,000 when all types are considered together. ${ }^{4}$ The leading cause of morbidity and mortality among patients with SMA revolves around respiratory complications: impaired coughing ability, hypoventilation, recurrent infections, and hypoplasia of the lungs and chest wall. ${ }^{17,18}$ Studies have shown the disruption in the SMN1 gene to be the cause of SMA. Although SMA is genotypically defined by the lack of SMN1, the clinical presentation and the overall severity of the disease state is determined mainly by the copy number of SMN2 gene present in an affected patient's genome. ${ }^{16}$ Since identifying the SMN1 gene locus in 1990 and its homologue SMN2 gene copy in 1995, a major effort has been devoted to providing potential therapeutic interventions such as replacing SMN1 or decreasing SMN2 exon skipping to increase the total amount of SMN proteins. ${ }^{3}$ Over the last 50 years, planned and realized applications in the field of antisense and nucleic acid nanotechnologies have produced astonishing results and posed new challenges for further developments, exemplifying the essence of the post-genomic era. ${ }^{57}$ ASOs are defined as chemically synthesized oligonucleotides, generally 12-30 nucleotides in length, designed to bind to RNA. ${ }^{58}$ The various sizes and chemical structures tend to determine 
Table 1. Clinical Safety and Efficacy

\begin{tabular}{|c|c|c|c|}
\hline $\begin{array}{l}\text { Author } \\
\text { (Year) }\end{array}$ & Groups Studied and Intervention & Results and Findings & Conclusions \\
\hline $\begin{array}{l}\text { Chiriboga } \\
\text { C. et al. } \\
(2016)^{47}\end{array}$ & $\begin{array}{l}\text { Phase I, open-label dose- } \\
\text { escalation study. Participants ( } n= \\
\text { 28) were patients with SMA } \\
\text { types } 2 \text { or } 3 \text {, aged } 2-14 \text { years. } \\
\text { Nusinersen was given in } 1,3,6 \text {, } \\
\text { and } 9 \text { mg doses. The authors } \\
\text { monitored adverse events and } \\
\text { examined the pharmacokinetics } \\
\text { of the drug in CSF and plasma. } \\
\text { HFMSE scores were evaluated at } \\
3 \text { months and 9-14 months post- } \\
\text { dose. }\end{array}$ & $\begin{array}{l}\text { No serious adverse events were } \\
\text { reported, and the safety of the } \\
\text { drug was established. Plasma and } \\
\text { CSF drug levels were dose- } \\
\text { dependent, and the drug had a } \\
\text { half-life in CSF of } 4-6 \text { months. } \\
\text { Significant increases from } \\
\text { baseline in HFMSE for the } 9 \text { mg } \\
\text { dose cohort were observed at } 3 \\
\text { months post-dose ( } 3.1 \text { points; } p= \\
\text { 0.016) and } 9-14 \text { months post- } \\
\text { dose (5.8 points; } p=0.008 \text { ). }\end{array}$ & $\begin{array}{l}\text { Nusinersen was safe, well- } \\
\text { tolerated, and showed promising } \\
\text { preliminary clinical outcome data. }\end{array}$ \\
\hline $\begin{array}{l}\text { Darras B. et } \\
\text { al. }(2019)^{49}\end{array}$ & $\begin{array}{l}\text { Phase Ib/Ila, open-label, } \\
\text { multicenter, multiple-dose, dose- } \\
\text { escalation study. Participants ( } \mathrm{n}= \\
\text { 28) were patients with SMA } \\
\text { types } 2 \text { or } 3 \text {, aged } 2-15 \text { years. } 3 \\
\text { doses of } 3,6,9 \text {, or } 12 \mathrm{mg} \\
\text { nusinersen were administered } \\
\text { intrathecally over three sessions, } \\
\text { and safety was monitored } \\
\text { throughout the trial. The } \\
\text { extension involved } 4 \text { doses of } 12 \\
\text { mg administered at 6-month } \\
\text { intervals. Measures of motor } \\
\text { function were evaluated. }\end{array}$ & $\begin{array}{l}\text { Mean HFMSE scores, ULM } \\
\text { scores, and 6MWT distances had } \\
\text { improved (HFMSE: SMA type II, } \\
\text { +10.8 points; SMA type III, +1.8 } \\
\text { points; ULM: SMA type II, +4.0 } \\
\text { points; 6MWT: SMA type III, } \\
\text { +92.0 meters). Mean CMAP } \\
\text { values remained relatively stable, } \\
\text { and no children discontinued } \\
\text { treatment due to adverse events. }\end{array}$ & $\begin{array}{l}\text { Nusinersen yielded clinically } \\
\text { significant improvements in } \\
\text { motor function for patients with } \\
\text { later-onset SMA. }\end{array}$ \\
\hline $\begin{array}{l}\text { Finkel R. et } \\
\text { al. }(2016)^{51}\end{array}$ & $\begin{array}{l}\text { Phase II, open-label, multiple- } \\
\text { dose dose-escalation study. } \\
\text { Participants ( } \mathrm{n}=20 \text { ) were } \\
\text { patients with SMA type } 1.3 \text { doses } \\
\text { of } 6 \text { or } 12 \mathrm{mg} \text { nusinersen were } \\
\text { administered over three sessions. } \\
\text { Safety was assessed throughout } \\
\text { the trial. Event-free survival, } \\
\text { measures of motor function, and } \\
\text { pharmacokinetics of the drug in } \\
\text { autopsy tissue were evaluated. }\end{array}$ & $\begin{array}{l}\text { Authors observed incremental } \\
\text { achievements of motor } \\
\text { milestones }(p<0.0001) \text {, } \\
\text { improvements in CHOP-INTEND } \\
\text { motor function scores ( } p= \\
0.0013) \text {, and increased } \\
\text { compound muscle action } \\
\text { potential amplitude of the ulnar } \\
\text { nerve }(p=0.0103) \text { and peroneal } \\
\text { nerve }(p<0.0001), \text { compared } \\
\text { with baseline. Autopsy showed } \\
\text { the distribution of the drug in } \\
\text { motor neurons in the spinal cord. } \\
\text { Adverse events were reported, } \\
\text { but authors considered them } \\
\text { unrelated to the study drug. }\end{array}$ & $\begin{array}{l}\text { Nusinersen is safe for use in } \\
\text { patients with infantile-onset } \\
\text { SMA, has pharmacokinetics } \\
\text { consistent with its mechanism of } \\
\text { action, and shows promising } \\
\text { clinical efficacy. }\end{array}$ \\
\hline $\begin{array}{l}\text { De Vivo D. } \\
\text { et al. } \\
\text { (NURTURE, } \\
2019)^{53}\end{array}$ & $\begin{array}{l}\text { Phase II, open-label. Participants } \\
(\mathrm{n}=25 \text { ) were asymptomatic, but } \\
\text { all were documented to have } \\
\text { homozygous deletions of the } \\
\text { SMN1 gene with variable } \\
\text { numbers of SMN2 gene copies. } \\
\text { Four doses of } 12 \text { mg nusinersen } \\
\text { were administered, followed by } \\
\text { maintenance dosing every } 119 \\
\text { days. Achievement of motor } \\
\text { milestones, event-free survival, } \\
\text { and need for ventilation was } \\
\text { analyzed } ~ 2.9 \text { years after the trial } \\
\text { began. }\end{array}$ & $\begin{array}{l}\text { Four participants with } \\
\text { two SMN2 copies utilized } \\
\text { respiratory support for } \geq 6 \mathrm{~h} / \mathrm{day} \\
\text { for } \geq 7 \text { consecutive days that was } \\
\text { initiated during acute, reversible } \\
\text { illnesses. All } 25 \text { participants } \\
\text { achieved the ability to sit without } \\
\text { support, } 23 / 25 \text { achieved walking } \\
\text { with assistance, and } 22 / 25 \\
\text { achieved walking independently. } \\
\text { Eight infants had adverse events } \\
\text { considered possibly related to } \\
\text { nusinersen by the study } \\
\text { investigators. }\end{array}$ & $\begin{array}{l}\text { Treatment of pre-symptomatic } \\
\text { SMA with nusinersen has an } \\
\text { acceptable safety level, and } \\
\text { evidence from the trial supports } \\
\text { its efficacy. }\end{array}$ \\
\hline $\begin{array}{l}\text { Finkel R. et } \\
\text { al. } \\
\text { (ENDEAR, } \\
2017)^{54}\end{array}$ & $\begin{array}{l}\text { Phase III, multicenter, double- } \\
\text { blind, placebo-controlled. } 121 \\
\text { symptomatic infants (nusinersen } \\
\text { group, } \mathrm{n}=80 \text {; placebo group, } \mathrm{n}= \\
\text { 41) were enrolled. Four doses of } \\
12 \text { mg nusinersen were } \\
\text { administered over } 4 \text { sessions. } \\
\text { Motor milestone achievements } \\
\text { and event-free survival were } \\
\text { compared between the drug }\end{array}$ & $\begin{array}{l}\text { A significantly higher percentage } \\
\text { of infants in the nusinersen group } \\
\text { vs. the control group had a motor } \\
\text { response ( } 51 \% \text { vs. } 0 \% \text { ), and the } \\
\text { likelihood of survival was also } \\
\text { higher (hazard ratio } 0.53, \mathrm{p}= \\
0.005 \text { ). Participants with a } \\
\text { shorter duration of illness at the } \\
\text { onset of treatment were more } \\
\text { likely to derive benefit. }\end{array}$ & $\begin{array}{l}\text { Nusinersen is effective in the } \\
\text { treatment of type } 1 \text { and type } 2 \\
\text { SMA. Early detection may be } \\
\text { critical for optimal treatment } \\
\text { outcomes. }\end{array}$ \\
\hline
\end{tabular}




\begin{tabular}{|c|c|c|c|}
\hline & group and placebo group. & & \\
\hline $\begin{array}{l}\text { Aragon- } \\
\text { Gawinska } \\
\text { K. et al. } \\
\text { (EAP, } \\
2018)^{55}\end{array}$ & $\begin{array}{l}\text { Phase III, extension trial for SMA } \\
\text { type } 1 \text { patients older than } 7 \\
\text { months. } 33 \text { children between } 8.3 \\
\text { and } 113.1 \text { months of age were } \\
\text { enrolled. Survival, respiratory, } \\
\text { and nutritional data were } \\
\text { collected. }\end{array}$ & $\begin{array}{l}\text { Median progress on the modified } \\
\text { HINE-2 score was } 1.5 \text { points after } \\
6 \text { months of treatment ( } p< \\
0.001) \text {. The need for respiratory } \\
\text { support significantly increased } \\
\text { over time. }\end{array}$ & $\begin{array}{l}\text { Nusinersen is also effective for } \\
\text { SMA type } 1 \text { in later stages of the } \\
\text { disease. }\end{array}$ \\
\hline $\begin{array}{l}\text { Mercuri E. } \\
\text { et al. } \\
\text { (CHERISH, } \\
2018)^{56}\end{array}$ & $\begin{array}{l}\text { Phase III, double-blind, placebo- } \\
\text { controlled. Participants ( } n=126 ; \\
n=84 \text { for the nusinersen group, } n \\
=42 \text { for the control group) all had } \\
\text { symptom onset after } 6 \text { months of } \\
\text { age and received } 4 \text { doses of } 12 \\
\text { mg nusinersen or } 4 \text { sham } \\
\text { procedures over } 4 \text { sessions. } \\
\text { Changes from the baseline of } \\
\text { HFMSE scores were evaluated. }\end{array}$ & $\begin{array}{l}\text { The least-squares mean an } \\
\text { increase in HFMSE score from } \\
\text { baseline to month } 15 \text { was } 4.0 \text { in } \\
\text { the nusinersen group and }-1.9 \text { in } \\
\text { the control group. } 57 \% \text { of the } \\
\text { nusinersen group had an increase } \\
\text { in HFMSE score of } \geq 3 \text { points, in } \\
\text { contrast to only } 26 \% \text { of the } \\
\text { control group ( } p<0.001 \text { ) }\end{array}$ & $\begin{array}{l}\text { Nusinersen is effective in the } \\
\text { treatment of later-onset (types } 2 \\
\text { and 3) SMA. }\end{array}$ \\
\hline
\end{tabular}

the specificity for its designated mRNA target, which modulates protein production. With the development of antisense technology came the FDA-approved nusinersen in 2016, which provided an optimistic approach to treating SMA and other neurodegenerative diseases. Compared to other pharmacologic treatment strategies mentioned, nusinersen has been shown to increase exon 7 inclusions to the SMN2 mRNA transcripts, enhancing SMN protein production and, thus, increasing the amount of full-length SMN proteins. It is available as an intrathecal injection requiring four initial loading doses followed by three maintenance injections annually supported by its long median half-life. Studies investigating the timing of drug delivery in mouse models of SMA report the best outcomes when drugs are delivered early before any significant motor function is lost. ${ }^{18,40}$ Phase III studies (CHERISH, ENDEAR, and NURTURE) have concluded to improve motor function in early and late-onset individuals and reduce the chances of ventilator requirements in pre-symptomatic infants. Nusinersen is a novel therapeutic approach that had consistent results in all three studies and is proof of the concept for treating SMA and other neurodegenerative disorders in the future.

Submitted: June 01, 2021 EST, Accepted: June 16, 2021 EST 


\section{REFERENCES}

1. Lunn MR, Wang CH. Spinal muscular atrophy. The Lancet. 2008;371(9630):2120-2133. doi:10.1016/S014 0-6736(08)60921-6

2. Kolb SJ, Kissel JT. Spinal Muscular Atrophy. Neurologic Clinics. 2015;33(4):831-846. doi:10.1016/ j.ncl.2015.07.004

3. Wurster CD, Ludolph AC. Nusinersen for spinal muscular atrophy. Therapeutic Advances in Neurological Disorders. 2018;11. doi:10.1177/1756285 618754459

4. Verhaart IEC, Robertson A, Wilson IJ, et al. Prevalence, incidence and carrier frequency of 5qlinked spinal muscular atrophy - A literature review. Orphanet Journal of Rare Diseases. 2017;12(1). doi:1 0.1186/s13023-017-0671-8

5. Kurland LT. Descriptive epidemiology of selected neurologic and myopathic disorders with particular reference to a survey in Rochester, Minnesota. Journal of Chronic Diseases. Published online 1958. doi:10.101 6/0021-9681(58)90002-X

6. Burd L, Short SK, Martsolf JT, Nelson RA.

Prevalence of type I spinal muscular atrophy in North Dakota. American Journal of Medical Genetics. Published online 1991. doi:10.1002/ajmg.1320410216

7. Tangsrud S - E, Halvorsen S. Child neuromuscular disease in Southern Norway: Prevalence, age and distribution of diagnosis with special reference to "non - Duchenne muscular dystrophy." Clinical Genetics. Published online 1988. doi:10.1111/i.1399-0 004.1988.tb02854.x

8. Darin N, Tulinius M. Neuromuscular disorders in childhood: A descriptive epidemiological study from western Sweden. Neuromuscular Disorders. Published online 2000. doi:10.1016/S0960-8966(99)00055-3

9. Chung BHY, Wong VCN, Ip P. Spinal muscular atrophy: Survival pattern and functional status. Pediatrics. Published online 2004. doi:10.1542/peds.2 $\underline{004-0668}$

10. Kolb SJ, Kissel JT. Spinal muscular atrophy: A timely review. Archives of Neurology. 2011;68(8):979-984. doi:10.1001/archneurol.2011.74

11. Farrar MA, Kiernan MC. The Genetics of Spinal Muscular Atrophy: Progress and Challenges. Neurotherapeutics. 2015;12(2):290-302. doi:10.1007/s 13311-014-0314-x
12. Ruggiu M, McGovern VL, Lotti F, et al. A Role for SMN Exon 7 Splicing in the Selective Vulnerability of Motor Neurons in Spinal Muscular Atrophy. Molecular and Cellular Biology. Published online 2012. doi:10.11 28/mcb.06077-11

13. Rossoll W, Jablonka S, Andreassi C, et al. Smn, the spinal muscular atrophy-determining gene product, modulates axon growth and localization of $\beta$-actin mRNA in growth cones of motoneurons. Journal of Cell Biology. Published online 2003. doi:10.1083/jcb.2 00304128

14. Zhang HL, Pan F, Hong D, Shenoy SM, Singer RH, Bassell GJ. Active transport of the survival motor neuron protein and the role of exon-7 in cytoplasmic localization. Journal of Neuroscience. Published online 2003. doi:10.1523/ineurosci.23-16-06627.2003

15. Chen YS, Shih HH, Chen TH, Kuo CH, Jong YJ. Prevalence and risk factors for feeding and swallowing difficulties in spinal muscular atrophy types II and III. Journal of Pediatrics. 2012;160(3):447-451.e1. doi:10.1016/j.jpeds.2011.0 8.016

16. Ross LF, Kwon JM. Spinal muscular atrophy: Past, present, and future. NeoReviews.

2019;20(8):e437-e451. doi:10.1542/neo.20-8-e437

17. Wang CH, Finkel RS, Bertini ES, et al. Consensus statement for standard of care in spinal muscular atrophy. Journal of Child Neurology. 2007;22(8):1027-1049. doi:10.1177/088307380730578 $\underline{8}$

18. Farrar MA, Park SB, Vucic S, et al. Emerging therapies and challenges in spinal muscular atrophy. Annals of Neurology. 2017;81(3):355-368. doi:10.1002/ ana.24864

19. Mehta NM, Newman H, Tarrant S, Graham RJ. Nutritional status and nutrient intake challenges in children with spinal muscular atrophy. Pediatric Neurology. 2016;57:80-83. doi:10.1016/i.pediatrneuro $\underline{1.2015 .12 .015}$

20. Davis RH, Godshall BJ, Seffrood E, et al. Nutritional practices at a glance: Spinal muscular atrophy type i nutrition survey findings. Journal of Child Neurology. 2014;29(11):1467-1472. doi:10.1177/ $\underline{0883073813503988}$ 
21. Fujak A, Raab W, Schuh A, Richter S, Forst R, Forst J. Natural course of scoliosis in proximal spinal muscular atrophy type II and IIIa: Descriptive clinical study with retrospective data collection of 126 patients. BMC Musculoskeletal Disorders. 2013;14:283. doi:10.1186/1471-2474-14-283

22. Chua K, Tan CY, Chen Z, et al. Long-term Followup of Pulmonary Function and Scoliosis in Patients with Duchenne's Muscular Dystrophy and Spinal Muscular Atrophy. Journal of Pediatric Orthopaedics. 2016;36(1):63-69. doi:10.1097/BPO.000000000000039 6

23. Suk KS, Baek JH, Park JO, et al. Postoperative quality of life in patients with progressive neuromuscular scoliosis and their parents. Spine Journal. 2015;15(3):446-453. doi:10.1016/i.spinee.201 $\underline{4.09 .030}$

24. Schorling DC, Pechmann A, Kirschner J. Advances in Treatment of Spinal Muscular Atrophy - New Phenotypes, New Challenges, New Implications for Care. Journal of Neuromuscular Diseases. 2020;7(1):1-13. doi:10.3233/JND-190424

25. Bharucha-Goebel D, Kaufmann P. Treatment Advances in Spinal Muscular Atrophy. Current Neurology and Neuroscience Reports. 2017;17(11):91. $\underline{\mathrm{d}}$ oi:10.1007/s11910-017-0798-y

26. Bertini E, Dessaud E, Mercuri E, et al. Safety and efficacy of olesoxime in patients with type 2 or nonambulatory type 3 spinal muscular atrophy: a randomised, double-blind, placebo-controlled phase 2 trial. The Lancet Neurology. 2017;16(7):513-522. do i:10.1016/S1474-4422(17)30085-6

27. Merlini L, Solari A, Vita G, et al. Role of gabapentin in spinal muscular atrophy: Results of a multicenter, randomized Italian study. Journal of Child Neurology. 2003;18(8):537-541. doi:10.1177/088 $\underline{30738030180080501}$

28. Russman BS, Iannaccone ST, Samaha FJ. A Phase 1 Trial of Riluzole in Spinal Muscular Atrophy. Archives of Neurology. 2003;60(11):1601-1603. doi:10.1001/arc hneur.60.11.1601

29. Miller RG, Moore DH, Dronsky V, et al. A placebocontrolled trial of gabapentin in spinal muscular atrophy. Journal of the Neurological Sciences. 2001;191(1-2):127-131. doi:10.1016/S0022-510X(01)0 0632-3

30. Rao VK, Kapp D, Schroth M. Gene Therapy for Spinal Muscular Atrophy: An Emerging Treatment Option for a Devastating Disease. Journal of managed care \& specialty pharmacy. 2018;24(12a):S3-S16. doi:1 0.18553/imcp.2018.24.12-a.s3
31. Calder AN, Androphy EJ, Hodgetts KJ. Small Molecules in Development for the Treatment of Spinal Muscular Atrophy. Journal of Medicinal Chemistry. 2016;59(22):10067-10083. doi:10.1021/ac s.jmedchem.6b00670

32. Andrews JA, Miller TM, Vijayakumar V, et al. CK-2127107 amplifies skeletal muscle response to nerve activation in humans. Muscle and Nerve. 2018;57(5):729-734. doi:10.1002/mus.26017

33. An Active Treatment Study of SRK-015 in Patients With Type 2 or Type 3 Spinal Muscular Atrophy - Full Text View - ClinicalTrials.gov. Published 2020. Accessed December 11, 2020. https://clinicaltrials.go v/ct2/show/NCT03921528

34. Stam M, Wadman RI, Wijngaarde CA, et al. Protocol for a phase II, monocentre, double-blind, placebo-controlled, cross-over trial to assess efficacy of pyridostigmine in patients with spinal muscular atrophy types 2-4 (SPACE trial). BMJ Open. 2018;8(7). doi:10.1136/bmjopen-2017-019932

35. Shorrock HK, Gillingwater TH, Groen EJN. Overview of Current Drugs and Molecules in Development for Spinal Muscular Atrophy Therapy. Drugs. 2018;78(3):293-305. doi:10.1007/s40265-018-0 $\underline{868-8}$

36. Charnas L, Voltz E, Pfister C, et al. Safety and efficacy findings in the first-in-human trial (FIH) of the oral splice modulator branaplam in type 1 spinal muscular atrophy (SMA): interim results.

Neuromuscular Disorders. 2017;27:S207-S208. doi:1 0.1016/j.nmd.2017.06.411

37. Mendell JR, Al-Zaidy S, Shell R, et al. Single-Dose Gene-Replacement Therapy for Spinal Muscular Atrophy. New England Journal of Medicine. 2017;377(18):1713-1722. doi:10.1056/nejmoa1706198

38. Swoboda KJ, Prior TW, Scott CB, et al. Natural history of denervation in SMA: Relation to age, SMN2 copy number, and function. Annals of Neurology. 2005;57(5):704-712. doi:10.1002/ana.20473

39. Glascock J, Sampson J, Haidet-Phillips A, et al. Treatment Algorithm for Infants Diagnosed with Spinal Muscular Atrophy through Newborn Screening. Journal of neuromuscular diseases. 2018;5(2):145-158. doi:10.3233/JND-180304

40. Phan HC, Taylor JL, Hannon H, Howell R. Newborn screening for spinal muscular atrophy: Anticipating an imminent need. Seminars in Perinatology. 2015;39(3):217-229. doi:10.1053/i.semp eri.2015.03.006 
41. Fda. HIGHLIGHTS OF PRESCRIBING

INFORMATION FULL PRESCRIBING INFORMATION: CONTENTS* 1 INDICATIONS AND USAGE 2 DOSAGE AND ADMINISTRATION 2.1 Dosing Information 2.2 Important Administration Instructions 2.3 Laboratory Testing and Monitoring to Assess Safety 3 DOS.

42. Nusinersen | DrugBank Online. Accessed December 11, 2020. https://go.drugbank.com/drugs/D $\underline{B 13161}$

43. Hoy SM. Nusinersen: First Global Approval. Drugs. Published online 2017. doi:10.1007/s40265-017-071 $\underline{1-7}$

44. Luu KT, Norris DA, Gunawan R, Henry S, Geary R, Wang Y. Population Pharmacokinetics of Nusinersen in the Cerebral Spinal Fluid and Plasma of Pediatric Patients With Spinal Muscular Atrophy Following Intrathecal Administrations. Journal of Clinical Pharmacology. 2017;57(8):1031-1041. doi:10.1002/jcp $\underline{\text { h. } 884}$

45. Biliouris K, Gaitonde P, Yin W, et al. A SemiMechanistic Population Pharmacokinetic Model of Nusinersen: An Antisense Oligonucleotide for the Treatment of Spinal Muscular Atrophy. CPT: Pharmacometrics and Systems Pharmacology. 2018;7(9):581-592. doi:10.1002/psp4.12323

46. Neil EE, Bisaccia EK. Nusinersen: A novel antisense oligonucleotide for the treatment of spinal muscular atrophy. Journal of Pediatric Pharmacology and Therapeutics. 2019;24(3):194-203. doi:10.5863/15 51-6776-24.3.194

47. Chiriboga CA, Swoboda KJ, Darras BT, et al. Results from a phase 1 study of nusinersen (ISIS-SMN $\mathrm{Rx}$ ) in children with spinal muscular atrophy. Neurology. 2016;86(10):890-897. doi:10.1212/WNL.00 $\underline{00000000002445}$

48. Haché M, Swoboda KJ, Sethna N, et al. Intrathecal Injections in Children with Spinal Muscular Atrophy: Nusinersen Clinical Trial Experience. Journal of Child Neurology. 2016;31(7):899-906. doi:10.1177/08830738 15627882

49. Darras BT, Chiriboga CA, Iannaccone ST, et al. Nusinersen in later-onset spinal muscular atrophy: Long-term results from the phase $1 / 2$ studies. Neurology. 2019;92(21):e2492-e2506. doi:10.1212/WN L.0000000000007527
50. Montes J, Dunaway Young S, Mazzone ES, et al. Nusinersen improves walking distance and reduces fatigue in later-onset spinal muscular atrophy. Muscle and Nerve. 2019;60(4):409-414. doi:10.1002/mus.2663 $\underline{3}$

51. Finkel RS, Chiriboga CA, Vajsar J, et al. Treatment of infantile-onset spinal muscular atrophy with nusinersen: a phase 2, open-label, dose-escalation study. The Lancet. 2016;388(10063):3017-3026. doi:1 $\underline{0.1016 / S 0140-6736(16) 31408-8}$

52. Kubo Y, Nishio H, Saito K. A new method for SMN1 and hybrid SMN gene analysis in spinal muscular atrophy using long-range PCR followed by sequencing. Journal of Human Genetics. 2015;60(5):233-239. doi:10.1038/jhg.2015.16

53. De Vivo DC, Bertini E, Swoboda KJ, et al. Nusinersen initiated in infants during the presymptomatic stage of spinal muscular atrophy: Interim efficacy and safety results from the Phase 2 NURTURE study. Neuromuscular Disorders. 2019;29(11):842-856. doi:10.1016/j.nmd.2019.09.007

54. Finkel RS, Mercuri E, Darras BT, et al. Nusinersen versus Sham Control in Infantile-Onset Spinal Muscular Atrophy. New England Journal of Medicine. 2017;377(18):1723-1732. doi:10.1056/nejmoa 1702752

55. Aragon-Gawinska K, Seferian AM, Daron A, et al. Nusinersen in patients older than 7 months with spinal muscular atrophy type 1. Neurology. 2018;91(14):E1312-E1318. doi:10.1212/WNL.0000000 $\underline{000006281}$

56. Mercuri E, Darras BT, Chiriboga CA, et al. Nusinersen versus Sham Control in Later-Onset Spinal Muscular Atrophy. New England Journal of Medicine. 2018;378(7):625-635. doi:10.1056/nejmoa1 $\underline{710504}$

57. Oberemok VV, Laikova VK, Repetskaya AI, et al. A half-century history of applications of antisense oligonucleotides in medicine, agriculture and forestry: we should continue the journey. Molecules. 2018;23(6). doi:10.3390/molecules23061302

58. Bennett CF. Therapeutic Antisense Oligonucleotides Are Coming of Age. Annual Review of Medicine. 2019;70(1):307-321. doi:10.1146/annurev-m ed-041217-010829 